\title{
Impairment of School performance, Psychological and Social Well- being and the Role of Counselors at Kalar Schools: A Qualitative Study
}

\author{
Nazdar Qudrat Abas \\ Department of Psychology, College of Education, University of Garmian
}

\begin{abstract}
School performance, psychological and social well-beings are the most challengeable tasks in taking care of adolescents. Well-being means positive relationships with others, personal mastery, autonomy, a feeling of purpose and meaning in life, and personal growth and development. School Counselors are usually working on improving the students' well-being psychologically and socially. The most common problems of teenagers are intimate relationships with opposite sex, disobeyed behaviors, neglecting home works. Despite these evidences, the role of school counselors still not well defined by the Government, the counselors are not well prepared during college studying years and after graduation, the number of counselors does not meet the students' needs, and sometimes they face obstacles doing the ir work by school administration. According to 20 counselors from different schools in Kalar, counselors are in need of continuous training courses, defining their roles by the Government and Ministry of Education, and providing them with the ir needs and rights such as having a room to meet students, giving them the chance to practice counseling.
\end{abstract}

\section{Introduction:}

Well-being or Wellness is the optimal state of health of individual and group (WHO, 2000). Well-being a positive outcome that is meaningful for people and for many sectors of society, because it tells us that people perceive that their lives are going well. Good living conditions (e.g., housing, employment) are fundamental to well-being (CDC, 2018). Adolescence is a critical period of growth and development; it includes a variety of physical, social, emotional and cognitive changes that mostly lead to problems, the most common problems among adolescents are related to growth and development, school, childhood illnesses that continue into adolescence, mental health disorders, and the consequences of risky or illegal behaviors, including injury, legal consequences (Sharon Levy, 2019). Other issues of independence, identity, sexuality, and relationships define this developmental stage. Mental health problems, such as mood disorders, anxiety disorders, and thought disorders (such as schizophrenia) as well as psychosocial disorders, may develop or first become apparent during adolescence. Suicide is a major cause of death for this age group (Sharon Levy, 2017). The role of school counselors is considered to be crucial during adolescence period, it is not only about addressing the adolescences' problems and offering simple helps, but the ir role are been expanded to direct and change the role of teenagers (Amatea \& Clark, 2005). The role of 
school counse lors still not well defined and there are a lot of ambiguity around their role and responsibilities (Lambie \& Williamson, 2004). School mangers, teachers and parents have different views about the importance of school counselors' role (Burnham \& Jackson, 2000), sometimes their role are seen positive and sometimes as negative (Khansa, 2015).

Garnefski and Diekstra (1996) in their study about "Perceived Social Support from Family, School, and Peers: Relationship with Emotional and Behavioral Problems among Adolescents" showed the importance of psychological support on minimizing the emotional and psychological problems among adolescents. Khansa, (2015) studied "Teachers' Perceptions toward School Counselors in Selected Private Schools in Lebanon" and has found positive and negative perspectives about school counslors. Al-Obaidi, et al (2005) assessed teachers' knowledge about children mental health needs in Baghdad, Iraq, most of the teachers admitted that they have poor know ledge about mental health and $70 \%$ of them agreed that they are in need of training coursed and development about mental health. Calvete and Cardenoso (2005) studied Gender Differences in Cognitive Vulnerability to Depression and Behavior Problems in Adolescents in Spain; they found huge differences between male and female adolescents regarding their cognitive vulnerability to depression and behavioral problems. Gau et al (2007) revealed that the adolescents who are practicing their activities during evening times (eveningness) are at greater risk for behavioral/emotional problems and risky behaviors compared to whom practice their activities in morning (morningness).

Iraq has been subjected to series of political conflicts and wars, adolescents are highly exposed to psychological and social problems (Shipp\& Clemens, 2005). Number of school counselors is so limited compared to number of schools and kindergartens, the total schools and kindergartens in Kalar are 250, while school counselors are only 102, taking in consideration that that some of these schools need more than one counselor (Directory of Education of Kalar). The school counselors and their roles are still not well known and \or well defined, especially in Iraq and mainly in Kurdistan Region. Despite the past and current conflicts in Iraq and its psychological and social impact on mental health, the lack of school counselors and their roles, poor orientation by teachers and parents regarding adolescence period; no studies have been made yet to address mental health and well-being among adolescence or to assess the problems that they are struggling with. For this reason the current study aims to the most common adolescents' problems addressed by school counselors in Kalar high schools and to assess the difficulties that the school counselors face in practicing role in schools.

\section{Methodology:}

A qualitative purposeful study design has been used for current study, the data were collected by interviews and the interview questions were designed by the researcher according to the study objectives, the interview composed of open ended questions about the most common adolescent problems at schools including male and female adolescents, the strategies that are used by the counselors to deal with those problems, the barriers that are faced and suggesting what are needed to be done in the future for improving school counselors' work. Study sample composed of twenty school counselors (five females, fifteen males) from different schools in Kalar, Sulaimaniyah- Kurdistan in November 2018. The sample was selected randomly and 
verbal consent was taken from each counselor before asking interview questions and after clarifying the study objectives. Inductive analys is method has been used to analyze the obtained data from the interview questions, the data have been classified according to their frequency and themes have been defined accordingly. The study has been carried out in high schools of Kalar - Sulaimaniyah, Kurdistan Region of Iraq. The sample of the study included twenty school counselors from twenty different high schools in Kalar. Kalar is a city in Iraq located on the west bank of the Sirwan river in Sulaimaniyah Governorate, Kalar is the administrative center of the Garmian district, It lies $140 \mathrm{~km}$ Southeast of Sula imaniyah and 30 $\mathrm{km}$ from the Iranian border. Kalar has a population of around 250,000 residents; Kalar takes pride in its historical background (Garmian Administration, 2015).

\section{Results:}

The results have been arranged according to the data obtained from the interviews into two different categories: adolescents' problems and School counselors' challenges. The most common problems among adolescents at Kalar schools that have been gathered from the school counselors has been themed according to the frequency of problems mentioned by school counselors into three major themes: impairment of school performance, intimate relationships with opposite sex, disobeyed behavior and other specific male and female problems. The school counselors' challenges are themed into two themes, first: lack of sufficient training, second: barriers created by school mangers and teachers.

According to the all 20 counselors that have been interviewed, the majority of the students in each classroom have poor performance in school tasks, despite the attempts by Ministry of Education in Kurdistan to improve the quality of education, the teachers and the curriculum are the same, but still the students' level of success are not optimistic. According to counselor (C 5); in each classroom there are only 4-6 students who success in all the subjects and also about 5-7 students whom fail in all the subjects, he quoted "I am surprised about the students' performance; they are neither doing the ir daily home works nor preparing themselves well for the examinations".

Counselor ( $\mathrm{C}$ 8) talked about the reasons and said "In general we can put the blame on the students, they are not trying hard, but in some classes it is the teaching methods that are used by some of the teacher and the way they treat their students which are not healthy and irresponsible".

Counselors (C 11, C 12, C 15, and C 20) showed worries about their passive role in dealing with students' poor performance, they said that the students are not seeking help, they are so hope less and hopeless, and they refuse to ask for counseling. Counselor (C 15) talked about a student that the counselor wanted to help him to improve his performance and offered him counseling sessions, but the student refused because he said that the counselor cannot help him, she said "the students are hopeless about the future of studying, they always say even if they work hard and get good grades, but at the end they will not be employed and they are just wasting their time, it is better to dropout school and find a job".

The second theme of problems is intimate relationships with opposite sex, almost all the adolescent students have intimate relationship problems, the culture forbids intimate relationships, but this has made them even worse, the students are together in daily school 
classes and they are in a sensitive developmental period, which they experience sexual identity and sexual orientation. The school directors have forbidden the existence of male and female students in their class without their teachers; they have caught intimate students doing inappropriate behaviors such as cuddling, sharing and holding hands (According to Kurdistan culture these kind of behaviors are not acceptable). Counselor (C 1) said "A female student has brought me a paper which a male student in the same class has written for her romantic words and asking her to be intimately close"; such cases are not acceptable so the student will be punished.

The third common problem is disobeyed behavior; in each there are 3-5 students whom are not obeying the school rules and the teachers' classroom rules. This case is mostly common in older students, whom have not passed in previous years and they are in a classroom with younger students. According to the counselors the main reason of disobeyed behaviors is the bad treatment of teachers with such students, they usually call them lazy and unable to success and this leads to aggressive and disobeyed behavior. An example about this was mentioned by Counselor (C 7) "the teacher is telling the student that he will not success this year either, it is better for him to drop out the school and start working with his father at grocery shop; this has made the younger students in the class to make fun of him and his response is aggressively beating them".

Another example of disobeyed behavior is a student who always talks at the classroom and never listens to the teacher and this makes the teacher to ask him to leave the class. Counselor (C 4) said "all the teacher complain about this student's disobeyed behavior and they have asked me to work on him, I have promised to change him, but it sounds very hard because he has problems with his parents as well, he is not listening to them as well'.

There are some other problems that are specific to male students such as smoking, fighting with peers, jumping over school walls and leaving the school before the end of the day. The other problems are female problems such as wearing make up for school, leaving school before the end of the day, school dropout especially when they cannot pass the examinations or when they get married.

The challenges that counselors face are two types, they do not have enough knowledge or information about their duties, counseling and psychotherapies. They are not well prepared for their carrier during college years or after employment, there is no training course for them to improve their abilities. The second challenge is the director of schools including the boss, teachers, students and their families. In some schools the boss prevents counseling sessions, so the counselors cannot practice their job. Some teachers do not agree to send their students for counseling session, especially during the class time and the rest time is very short (mostly five minutes) and the counselor cannot help the students. In some cases the students are not attending the counseling sessions, Counselor (C 3) quoted "some students cannot trust the counselor to share their personal information, because they have bad experiences with counselors whom shared their personal information with other and made their problems even bigger". Parents usually disagree with counseling because they refuse to take the advice of the counselors about how to deal with their children and they claim to know more than the counselors about taking care of their own children. 
Some of the counselors mentioned other problems such as unavailability of private room for counseling, limited time of the students, number of students is too much compared to number of supposed counselors (which is one counselor for each 200 students) and some of the schools do not have any counselor, poor collaboration of the teaching staff with counselors, Stigma of visiting counselors, the role of counselors is still not well defined and the community has poor knowledge about counseling.

\section{Discussion:}

The aim of the current study was to address the most common adolescent students' problems at Kalar high schools by school counselors and also to assess the barriers that school counselors face in practicing their role. The findings showed too many serious problems in Kalar schools and many serious challenges that school counselors face every day with their job. According to the results that have been presented, the students are suffering from bad parenting and bad treatment by teachers. Family support plays a great role in supporting adolescents and treating the ir social and psychological problems (Garnefski \& Diekstra, 1996). Strong relationships with parents during adolescence period decrease the chance of getting involved within bad sexual intimate relationships (Miller, 2002). There is a relationship between the religiosity and sexual behaviors in all societies, religious communities have less sexual relationships in adolescence period (Thornton \& Camburn, 1989). The bad parenting and poor orientation about adolescence by the parents and teachers have led to toxic relationships and wrong treatment of adolescents; on the other hand the adolescents' responses are aggressive, disobeying and converse behaviors.

The male students have more problems compared to females, this result disagrees with Emami, et al (2007) they found that adolescents girls had higher mental problems compared with male adolescents in Iran (Emami, et al 2007), also Calvete and Cardeñoso (2005) found that female adolescents had higher levels of negative thinking and poor problem orientation and higher levels of depression symptoms. While de Anda, et al (2000) have found high levels of stress and stressors among adolescents with no significant differences between males and females, but females compared to males had better coping strategies in dealing with stress. The culture plays a great role in Kalar schools, the culture norms requires shy, polite and obeyed girls unlike boys they have ultimate freedom and have to be strong and brave.

There is a relationship between the religios ity and sexual behaviors in all societies, religious communities have less sexual relationships in adolescence period (Thornton \& Camburn, 1989).

\section{Conclusion and Recommendations:}

The study have concluded that adolescent students are suffering from different serious psychological and social problems and poor academic performance, the male students have more problems compared with males and some of the problems are different in males and females. The most common problems that the students have are intimate relationships with opposite sex, poor academic performance and disobeyed behaviors. 
The number of counselors is not enough at Kalar high schools and they are not well prepared to practice their role. The counselors are facing barriers and difficulties in the ir job by the school directory, teaching staff, parents and students.

The study recommends defining the role, duties and responsibilities of school counselors by Ministry of Education, providing more counselors for the schools to meet the students' needs and preparing the counselors for their job by providing periodic training courses.

Providing orientation for parents and the teaching staffs about the importance of counseling through seminars, workshops and training courses to facilitate the counselors work and cooperate together for helping the students. Future studies required to get more understanding about adolescent needs and problems from their perspective, studies about adolescents' parents to assess their challenges in dealing with adolescence period, parents' perspective about the role of school counselors and also about the school counselors' needs and challenges that they face in dealing with adolescent students and with their parents.

\section{References:}

1. Al-Obaidi, A. K., Nelson, B. D., Al Badawi, G., Hicks, M. H. R., \& Guarino, A. J. (2013). Child mental health and service needs in Iraq: beliefs and attitudes of primary school teachers. Child and Adolescent Mental Health, 18(3), 171-179.

2. Amatea, E. S., \& Clark, M. A. (2005). Changing schools, changing counselors: A qualitative study of school administrators' conceptions of the school counselor role. Professional School Counseling, 9(1), 2156759X0500900101.

3. Burnham, J. J., \& Jackson, C. M. (2000). School counselor roles: Discrepancies between actual practice and existing models. Professional schoolcounseling, 4(1), 41.

4. Calvete, E., \& Cardeñoso, O. (2005). Gender differences in cognitive vulnerability to depression and behavior problems in adolescents. Journal of Abnormal Child Psychology, 33(2), 179-192.

5. Center for Chronic Disease Prevention and Health Promotion (CDC). (2018) Well-Being Concepts. Division of Population Health. (Web). Accessed February 10TH 2019.

6. de Anda, D., Baroni, S., Boskin, L., Buchwald, L., Morgan, J., Ow, J., ... \& Weiss, R. (2000). Stress, stressors and coping among high schoolstudents. Children and youth services review, 22(6), 441-463.

7. Emami, H., Ghazinour, M., Rezaeishiraz, H., \& Richter, J. (2007). Mental health of adolescents in Tehran, Iran. Journal of Adolescent Health, 41(6), 571-576.

8. Garmian Admin istration. (2015). Kalar. Official Site of General Tourism of Kurdistan - Iraq. (Web). Accessed February 10th 2019.

9. Garnefski, N., \& Diekstra, R. F. (1996). Perceived social support from family, school, and peers: Relationship with emotional and behavioral problems among adolescents. Journal of the American academy of Child \& adolescent Psychiatry, 35(12), 1657-1664.

10. Gau, S. S. F., Shang, C. Y., Merikangas, K. R., Chiu, Y. N., Soong, W. T., \& Cheng, A. T. A. (2007). Association between morningness-eveningness and behavioral/emotional problems among adolescents. Journal of biological rhythms, 22(3), 268-274

11. Khansa, R. (2015). Teachers' Perceptions toward School Counselors in Selected Private Schools in Lebanon. Procedia-Social and Behavioral Sciences, 185, 381-387.

12. Lambie, G. W., \& Williamson, L. L. (2004). The challenge to change from guidance couns eling to professional schoolcounseling: A historical proposition. Professional School Counseling, 124-131.

13. Miller, B. C. (2002). Family influences on adolescent sexual and contraceptive behavior. Journal of sex research, 39(1), 22-26. 
14. Sharon Levy. (2017). Introduction to Problems in Adolescents. Harvard Medical School; Director, Adolescent Substance Abuse Program, Boston Children's Hospital (Web). Accessed February 10th 2019.

15. Sharon Levy. (2019). Introduction to Problems in Adolescents. Harvard Medical School; Director, Adolescent Substance Abuse Program, Boston Children's Hospital (Web). Accessed February 10th 2019.

16. Shipp, A. E., \& Clemens, E. V. (2005). Counseling adolescent students affected by the war in Iraq: using history as a guide. Professional School Counseling, 9(4), 2156759X0500900418.

17. Thornton, A., \& Camburn, D. (1989). Religious participation and adolescent sexual behavior and attitudes. Journal of Marriage and the Family, 641-653. 